(2) Open Access Full Text Article

REVIEW

\title{
Hepatocellular carcinoma in elderly patients: challenges and solutions
}

\author{
This article was published in the following Dove Press journal: \\ Journal of Hepatocellular Carcinoma \\ 17 June 2016 \\ Number of times this article has been viewed
}

\section{Angélique Brunot \\ Samuel Le Sourd \\ Marc Pracht \\ Julien Edeline}

Department of Medical Oncology, Centre Eugene Marquis, Rennes, France
Correspondence: Julien Edeline

Department of Medical Oncology, Centre Eugene Marquis, Avenue de la Bataille Flandres-Dunkerque, 35043 Rennes, France

Tel +33299253196

Email j.edeline@rennes.unicancer.fr
Abstract: Hepatocellular carcinoma (HCC) is the second most common cause of death by cancer in the world. Due to the delayed HCC development in hepatitis C carriers and nonalcoholic fatty liver disease, the incidence of HCC in the elderly is increasing and is becoming a global health issue. Elderly patients with HCC should be assessed through proper oncologic approach, namely, screening tools for frailty (Geriatric-8 or Vulnerable Elders Survey-13) and comprehensive geriatric assessment. This review of the literature supports the same treatment options for elderly patients as for younger patients, in elderly patients selected as fit following proper oncogeriatric assessment. Unfit patients should be managed through a multidisciplinary team involving both oncological and geriatrician professionals. Specific studies and recommendations for HCC in the elderly should be encouraged.

Keywords: liver cancer, treatment, surgery, geriatric evaluation, sorafenib

\section{Introduction}

Management of cancer in elderly patients is becoming a global issue, due to the constant rise of life expectancy during last decades. ${ }^{1}$ In developed countries, population older than 65 years will represent $20 \%$ of the general population in 2025, and this population is more at risk to develop malignant diseases. ${ }^{2}$ Currently, in the US and in Europe, $>60 \%$ of newly diagnosed cancer and $70 \%$ of death-related cancer arise in this population. ${ }^{3}$

Consequently, it is expected that the number of older patients requiring specific oncologic management will steadily increase.

One of the most frequent diagnosed cancers in the world (fifth range in men), particularly in the elderly, is hepatocellular carcinoma (HCC), and its incidence regularly increases. HCC is currently the second cancer-related cause of death in men worldwide. $^{4}$

$\mathrm{HCC}$ is generally diagnosed in middle-aged and elderly populations, most of the time in a context of cirrhotic liver, and its incidence is expected to increase. Different epidemiological factors could explain this occurrence, such as the rising incidence of noninfectious cirrhosis liver, which develops later in the life. Furthermore, the development of vaccination and antiviral therapies improves the long-term control of chronic $\mathrm{B}$ or $\mathrm{C}$ hepatitis but delays the occurrence of liver cirrhosis and the development of HCC. Moreover, hepatitis C virus (HCV) contamination generally occurs in adult age and presents more severe consequences in older patients, such as severe histological damages and more liver cirrhosis. The latter represents a major part of the cause of HCC in elderly patients. ${ }^{5,6}$ 
As elderly patients are at increased risk of other comorbidities, such as diabetes, renal failure, pulmonary and cardiovascular diseases, or other risk factors, optimal treatment strategy may be difficult to define. Consequently, for this population, there is a risk to be either undertreated, meaning the nondelivery of standard treatment only due to the age, in patients, however, fit to receive it, or overtreated, meaning the administration of the standard treatment despite the frailty of the patient, which could cause severe toxicities or geriatric failure.

To date, results of most studies do not find any difference in term of treatment outcomes comparing elderly and young patients, including studies comparing different treatment procedures. ${ }^{6-13}$ However, there is a lack of data concerning prognostic factors of survival for elderly patients with cancer, due to the few numbers of prospective studies using geriatric assessment tools. We will review in this article the existing literature regarding each $\mathrm{HCC}$ treatment modality.

Treatment of HCC considerably improved since last decades, with the development of new ablative procedures and improvement of surgery. Optimal treatment strategy is currently defined according to several clinical, biological, and radiological factors, such as liver function, performance status, characteristics of tumors, and coexistence of comorbidities. ${ }^{14}$

The Barcelona Clinic Liver Cancer (BCLC) classification is the standard classification of $\mathrm{HCC}$, including four prognostic factors of $\mathrm{HCC}$, and defines treatment recommendations according to each stage. This classification includes five stages ( $0, \mathrm{~A}, \mathrm{~B}, \mathrm{C}$, and $\mathrm{D})$.

Stage 0 (very early stage) includes tumor measuring $<2$ $\mathrm{cm}$, with a Child-Pugh score A and Eastern Cooperative Oncology Group Performance Status (ECOG-PS) 0. Stage A includes single tumor measuring $>2 \mathrm{~cm}$ or three nodules measuring $<3 \mathrm{~cm}$ of diameter, with a Child-Pugh score A or $\mathrm{B}$ and ECOG-PS 0. Median overall survival (OS) at 5 years is $\sim 50 \%-70 \%$ with a curative treatment, such as surgery or local ablative procedure. Stage B is referred to as intermediate stage and includes patients presenting asymptomatic multiples nodules, Child-Pugh score A or B, and ECOGPS 0 . Overall median survival is estimated at 16 months, extended to 19-20 months after chemoembolization. Stage $\mathrm{C}$ is defined as advanced stage, for patients with symptomatic (ECOG-PS 1-2) or metastatic tumor, macrovascular invasion, and Child-Pugh score A or B. Prognosis of these patients is poor with a median OS of 6 months, and standard treatment is sorafenib. And finally, stage D includes patients with either liver decompensation (Child-Pugh score C) or altered performance status $(>2)$, and only supportive care could be proposed. ${ }^{14}$
According to the different factors previously listed, several treatments are currently available. Curative treatments are surgical with either surgical resection (SR) or liver transplantation (LT) and percutaneous ablative treatment by radiofrequency (RFA) or percutaneous ethanol injection (PEI). Other treatments are considered as palliative treatment, including transarterial chemoembolization (TACE) and radioembolization for BCLC intermediate stages, and targeted therapies for advanced stages (sorafenib is the only systemic treatment validated in this indication). ${ }^{14}$

However, among factors allowing to define optimal treatment for patients with HCC, age is never quoted. This current situation highlights the need to investigate and identify the optimal treatment of $\mathrm{HCC}$ in elderly patients. In this review, we mainly described current knowledge of clinical characteristics, treatments purposed, and outcome of elderly patients with HCC.

\section{Who is an elderly patient?}

We should acknowledge that a same chronological age might be associated with very different functional status; moreover, the cutoff used to define "elderly" patients is varying across studies.

Thus, elderly patients are aged from 65 years according to studies dating from 1980 s to $>75$ years according to reports from 1990 to present. ${ }^{15}$

Moreover, due to the increase of life expectancy, the number of patients with HCC aged $>80$ years (very elderly patients) has been steadily increasing, and recent studies begin to focus on this specific population. ${ }^{16}$

The challenge of managing the elderly patients is to assess the benefit over risk ratio, meaning to define when the expected benefit of treatment is superior to the risk of toxicity in this elderly population, which has a decline of its life expectancy and less adaptation to physical and psychological stress. This evaluation may be more difficult in the elderly population, which requires specific evaluation using appropriate tools. ${ }^{17}$

Assessment of comorbidity seems to be necessary when describing these elderly patients; however, there is some controversy about how to define it and stratify the risk of death secondary to the number and severity of associated comorbidities. Several comorbidity scales have been proposed to quantify this risk for patients, and to determine the state of frailty for them. Frailty is defined as the state of vulnerability to poor resolution of homeostasis following a stressor event. Frailty is not rare; it concerned $10 \%$ of 65 years and over, 
rising to $25 \%-50 \%$ for people aged 85 years and more. This state of frailty is significantly increased with the stress of cancer and treatment administrated by oncologist. ${ }^{18}$

One of the most established approaches to identify frailty is the comprehensive geriatric assessment (CGA). CGA is a global and multidisciplinary evaluation that leads to the proposal of an individualized treatment plan. As the best clinical test for the identification of frailty, it is increasingly used in standard care, but its wider adoption is limited by resource allocation. ${ }^{19}$

The basis of the CGA is the global and multidisciplinary assessment. Multidisciplinary because it includes not only geriatricians but paramedical staff, such as nurses, social worker, nutritionist, and more, and global because CGA takes into account not only medical diagnosis but also environmental and social context of patient, which can also affect patient's well-being. CGA allows to identify and highlight patient's difficulties that can impact the treatment and to offer the most appropriate management. Ultimately, it provides and coordinates a global plan for treatment, rehabilitation, support, and long-term care.

CGA proved in several studies its significant benefit compared to standard care, used to less complex patients, such as evaluation by only oncologist, without evaluation of multidisciplinary staff. This benefit concerned the increase of autonomy and reduction of mortality for patient benefiting from CGA, as it was showed in the Stuck et $\mathrm{al}^{20}$ study (odds ratio [OR] 0.73 at 6 months for reduction of mortality, confidence interval $[\mathrm{CI}]$ : $0.61-0.88)$. These results were confirmed by a Cochrane review led in 2011, showing a significant reduction in death or functional decline (OR 0.76 , CI: $0.64-0.90$ at 6 months). Interestingly, this review also found a positive correlation between the use of CGA and a higher chance to being alive and at home at 6 months (OR 1.31, CI: 1.15-1.49). This could be equivalent to a number needed to assess 13 patients to avoid one death or admission in residential care. ${ }^{21}$ Of note, no specific study was performed in patients with $\mathrm{HCC}$, but only either in more general context or in other populations.

\section{Geriatric screening tools}

Decoster et $\mathrm{al}^{22}$ updated in a recent review the International Society of Geriatric Oncology 2005 recommendations about the use of tools and scale to identify elderly patients who need a geriatric evaluation, such as CGA. Approximately 50 studies evaluating the use of 17 different screening tools in elderly patients with cancer were identified. The most studied tools are Geriatric-8 (G-8) and Vulnerable Elders
Survey-13 (VES-13), presented in Table 1 and Table 2, respectively.

\section{Geriatric-8}

The G-8 is a scale including eight items, which covers in approximately 5 minutes multiple domains assessed by the geriatrician in CGA (Table 1). ${ }^{23}$ This scale is graded from 0 to 17 . A score $<14$ is abnormal and requires a specific geriatric evaluation. ${ }^{24}$

Table I The Geriatric-8 questionnaire

\begin{tabular}{|c|c|}
\hline Items & $\begin{array}{l}\text { Possible responses } \\
\text { (score) }\end{array}$ \\
\hline $\begin{array}{l}\text { Has food intake declined over the past } \\
3 \text { months due to loss of appetite, digestive } \\
\text { problems, chewing, or swallowing difficulties? }\end{array}$ & $\begin{aligned} 0= & \text { severe decrease in } \\
& \text { food intake } \\
\mathrm{I}= & \text { moderate } \\
& \text { decrease in food } \\
& \text { intake } \\
2= & \text { no decrease in } \\
& \text { food intake }\end{aligned}$ \\
\hline Weight loss during last 3 months? & $\begin{aligned} 0= & \text { weight loss }>3 \mathrm{~kg} \\
\mathrm{I}= & \text { does not know } \\
2= & \text { weight loss } \\
& \text { between I and } \\
& 3 \mathrm{~kg}\end{aligned}$ \\
\hline Mobility? & $\begin{aligned} 0= & \text { bed or chair } \\
& \text { bound } \\
\mathrm{I}= & \text { able to get out of } \\
& \text { bed } / \text { chair but does } \\
& \text { not go out } \\
2= & \text { goes out }\end{aligned}$ \\
\hline Neuropsychological problems? & $\begin{aligned} 0= & \text { severe dementia } \\
& \text { or depression } \\
1= & \text { mild dementia } \\
2= & \text { no psychological } \\
& \text { problems }\end{aligned}$ \\
\hline BMI? (weight in $\mathrm{kg}$ )/(height in $\mathrm{m}^{2}$ ) & $\begin{array}{l}0=\mathrm{BMI}<19 \\
\mathrm{I}=\mathrm{BMI} 19 \text { to }<2 \mathrm{I} \\
2=\mathrm{BMI} 2 \mathrm{I} \text { to }>23 \\
3=\mathrm{BMI} \geq 23\end{array}$ \\
\hline $\begin{array}{l}\text { Takes more than three prescription drugs } \\
\text { per day? }\end{array}$ & $\begin{array}{l}0=\text { yes } \\
\mathrm{I}=\text { no }\end{array}$ \\
\hline $\begin{array}{l}\text { In comparison with other people of the } \\
\text { same age, how does the patient consider } \\
\text { his/her health status? }\end{array}$ & $\begin{array}{l}0.0=\text { not as good } \\
0.5=\text { does not know } \\
1.0=\text { as good } \\
2.0=\text { better }\end{array}$ \\
\hline Age & $\begin{array}{l}0:>85 \\
\mathrm{I}: 80-85 \\
2:<80\end{array}$ \\
\hline Total score & $0-17$ \\
\hline
\end{tabular}

Note: () The Author 2012. Published by Oxford University Press on behalf of the European Society for Medical Oncology. All rights reserved. Reproduced with permission from the Author, from Bellera CA, Rainfray M, Mathoulin-Pélissier S, et al. Screening older cancer patients: first evaluation of the G-8 geriatric screening tool. Ann Oncol. 20I 2;23(8):2166-2। $72 .^{23}$

Abbreviation: BMI, body mass index. 
Table 2 Adaptation of the Vulnerable Elders Survey I3 (VES-13) questionnaire

\begin{tabular}{ll}
\hline Items & Score \\
\hline Age & I \\
- 75-85 years & 3 \\
- >85 years & \\
Self-evaluation of your health & 0 \\
- Excellent & 0 \\
- Very good & 0 \\
- Good & I \\
- Fair & I \\
- Poor & \\
Do you have difficulty with the following activities: & I \\
- Stopping, crouching, or kneeling? & I \\
- Lifting or carrying objects as heavy as 5 kg? & I \\
- Reaching or extending arms above shoulder level? & I \\
- Heavy housework such as scrubbing floors or washing & I \\
windows? & I \\
- Writing or handling and grasping small objects? & \\
- Walking 500 m? & I \\
Because of your health or physical condition, do you need \\
help for: \\
- Shopping for personal items? \\
- Managing money? \\
- Walking across the room (use of a cane or walker is okay)? \\
- Doing light housework? \\
- Bathing or showering? \\
\hline Notes:Adat
\end{tabular}

Notes: Adapted from Saliba D, Elliott M, Rubenstein LZ, et al. The vulnerable elders survey: a tool for identifying vulnerable older people in the community. J Am Geriatr

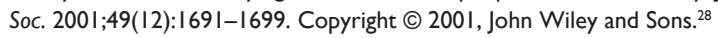

G-8 was evaluated in several prospective studies, ${ }^{24-26}$ and all of them showed that it was a predictive of chemotherapyrelated toxicity $(P=0.025)^{26}$ and prognostic of survival in various solid cancers.

\section{Vulnerable Elders Survey- 13}

This tool includes 13 items, completed in 5 minutes, to recognize elderly people with an increase risk of health deterioration but not specific to cancer (Table 2) ${ }^{27} \mathrm{~A}$ score $>3$ reflects a state vulnerability, defined as an increased risk of functional decline or death over 2 years. ${ }^{28}$

In three studies, ${ }^{26,28,29}$ VES-13 was correlated to treatmentrelated side effects, and for cancers it was predictive for the occurrence of severe chemotherapy-related toxicity $(P=0.015){ }^{26}$ More specifically, VES-13 is associated with $\operatorname{survival}(P<0.001)$ for digestive cancers treated with chemotherapy. ${ }^{29}$

\section{Combination of VES-I 3 and G-8}

VES-13 and G-8 are considered the best geriatric tools established to predict treatment-related toxicity and also survival after treatment. Combination or comparison of this two scores were evaluated in two studies and suggested that it would be a sensitive and specific screening tool in older patient; in the
Soubeyran's study, ${ }^{27}$ sensitivity and specificity were $86.6 \%$ and $53.2 \%$, respectively, for detection of unfit patient after CGA in case of abnormal score on either G-8 or VES-13 test. Pottel et a ${ }^{30}$ found in this study a sensitivity and specificity at $91.4 \%$ and $93.8 \%$, respectively, in case of VES- $13+(17-\mathrm{G} 8)$ $\geq 5$. This study also shows that the combination of both G-8 and VES-13 score is better than G-8 and VES-13 alone in terms of positive and negative predictive values.

To summarize, G-8 and VES-13, alone and in combination, are the most validated screening tools to assess the risk of frailty. However, it is essential to highlight that these tools should only be applied with the goal to better select patients at need for a CGA and not to replace it. Moreover, no specific study in patients with HCC was performed.

\section{Clinical characteristics of HCC in elderly patients}

Although there is no liver disease specific to elderly patients, natural evolution of liver disease seems to be different, in several aspects, than in younger patients, particularly the process of liver carcinogenesis. ${ }^{31}$ First, most studies showed that elderly patients with HCC were more likely women, which maybe due to their longer life expectancy. ${ }^{6,9,12,13,32-36}$ Concerning the etiology of HCC, elderly patients more likely suffer from $\mathrm{HCV}^{6,9,12,13,32-36}$ In fact, unlike hepatitis B virus (HBV) infection, most $\mathrm{HCV}$ infections are acquired late in life, and HCV-related carcinogenesis needs a long delay to appear. Thus, HCV-related HCC is delayed by approximately 10 years compared to HBV-related HCC ${ }^{37}$ However, in a recent review focusing on hepatectomy in elderly patients with HCC, Oishi et $\mathrm{al}^{8}$ highlighted that elderly patients suffered less from HCV or HBV infection than younger patients, implying other etiological factors. Among them, nonalcoholic-steatohepatitis syndrome seems to play an important role in the carcinogenesis of HCC in elderly patient. The phenomenon of hepatic steatosis and nonalcoholic fatty liver disease is related to the metabolic syndrome, involving obesity, dyslipidemia, hypertension, sleep apnea, and diabetes mellitus type $2{ }^{38,39}$ Visceral fat accumulation is frequently recorded in patients with nonalcoholic fatty liver disease/nonalcoholic-steatohepatitis, which leads to insulin resistance and hyperinsulinemia that can accelerate hepatocarcinogenesis, particularly in elderly people. However, in older patients with HCC, prevalence of healthy liver is higher than younger patients. It suggests that age is an independent risk factor to develop HCC, as supported by the study of Isokawa. ${ }^{40}$ 
With respect to the pathology of HCC at presentation, several studies reported that in elderly patients, HCC is more frequently mono- or pauci-focal and is frequently associated with less advanced fibrosis. Multifocal liver tumors are associated with the severity of liver fibrosis while, with aging, carcinogenesis has much more time to progress even in the absence of significant inflammation and fibrosis. ${ }^{6,9,13,31,34-36}$ It has been reported that HCC in elderly patient was more frequently encapsulated, which is a favorable prognostic factor for HCC being associated with greater differentiation and lower incidence of vascular invasion. ${ }^{37}$

In summary, female sex and $\mathrm{HCV}$ infection are more frequent in elderly patients presenting HCC than in younger patients. The carcinogenesis process is also different between these two groups; for older patients, the degree of background liver fibrosis is lower. Finally, aging is closely associated with liver carcinogenesis.

\section{Surgical treatment Liver transplantation}

Orthotopic liver transplant (OLT) is a curative treatment for HCC. Due to the organ shortage, access to OLT is still narrowed, and age is one of the most important variables limiting access. Living donor transplant may be an adequate option even for older patients, but living donor transplant programs are still limited or not available in many countries. Although there is no established age limit for OLT, an arbitrary threshold of most countries generally adopts $65-70$ years. Elderly patients are considered poor candidates due to the frequent presence of ischemic heart disease and diabetes, which are known to adversely affect post-OLT course.

The place of OLT for elderly patients is currently not clear, due to contradictory studies. In his review, Keswani et $\mathrm{al}^{41}$ did not find any difference in short-term survival between elderly and younger patients (with a cutoff at 60 years old) who received liver transplantation (LT). Thus, age alone should not exclude a patient from LT. However, longterm survival results of elderly seem to be worse than younger due to higher rate of postoperative complications, such as malignancy and heart disease. More recently, these results were supported by Kim et al, ${ }^{42}$ which studied outcome in a large cohort of 10,238 patients who underwent OLT for HCC. Although OS was prolonged in younger patients, there was no difference in term of specific disease survival between the two groups, with a cutoff at 65 years old. These results suggested that beyond this age, for patients carefully selected, OLT is an acceptable treatment of HCC. However, due to the lack of liver donors, an extension of the age limit for transplantation may affect negatively the transplantation access for younger and probably explain the current limitations to transplant in elderly patients. Japanese health authorities allow the livingdonor partial OLT for the treatment of HCC developed on liver cirrhosis, when the Milan criteria are satisfied, because of the lack of brain dead donors in Japan. ${ }^{35}$

\section{Surgical resection}

Along with OLT, SR is a curative treatment of resectable HCC. Furthermore, with the improvement of surgical technology and perioperative management, SR for elderly patient with HCC has become safer. ${ }^{43}$ To date, according to the European Association for the Study of Liver (EASL) guidelines, SR is indicated for a HCC BCLC stage $0 .{ }^{14}$ Due to the lack of liver donor and good survival outcomes, some authors proposed this procedure as first-line treatment for HCC, instead of OLT.

There have been several studies focusing on the outcomes and safety in elderly patients with HCC treated with SR (Table 3). 6,8,9,13,34-36,44-46 In two studies, Huang et $\mathrm{al}^{9}$ and Kaibori et $\mathrm{al}^{46}$ reported outcomes and prognostic factors of 2,283 and 488 elderly patients, respectively, with HCC undergoing hepatectomy for HCC. They compared patients aged 70 years or more and younger, and both studies did not find significant differences in disease-free survival and OS between the two groups. These results are supported by several other studies in terms of survival outcomes, but more postoperative complications were observed in elderly patients, such as delirium, longer hospital stay, and frequent discharge to a rehabilitation institution..$^{6,8,47,48}$

Two recent studies reported results of hepatectomy in a very elderly population, aged $>80$ years $(n=20$ and eleven patients). ${ }^{15,49}$ Both studies did not show any survival difference between the two groups $(<80$ years and $\geq 80$ years), but Nozawa et $\mathrm{al}^{15}$ reported more postoperative cardiovascular complications and delirium in the very elderly group, while no difference was seen in the Yamada's study. Finally, Sulpice et al ${ }^{50}$ reviewed liver resections for HCC in 992 patients, including 152 aged $\geq 75$ years. They found that age $\geq 75$ years was independently associated with postoperative mortality (OR 4.75, 95\% CI: 1.5-15.1; $P=0.008$ ) and 1-year mortality (OR 2.8, 95\% CI: 1.2-6.6; $P=0.015)$, and thus represents a risk factor for death after a liver resection.

To summarize, elderly patients with HCC who underwent SR had similar survival outcomes compared with younger patients, including very elderly patients aged 80 years or more (Table 3). However, caution should be taken as more 
Table 3 Main results of studies comparing elderly and younger patients with hepatocellular carcinoma undergoing liver resection

\begin{tabular}{|c|c|c|c|c|}
\hline $\begin{array}{l}\text { Reference } \\
\text { (year) }\end{array}$ & $\begin{array}{l}\text { Age limit } \\
\text { (years) }\end{array}$ & $\begin{array}{l}\text { Elderly/younger } \\
\text { patients }(n)\end{array}$ & Treatments & Major findings \\
\hline $\begin{array}{l}\text { Kim et al } \\
(2014)^{42}\end{array}$ & 65 & $1,613 / 8,625$ & OLT & $\begin{array}{l}\text { Longer OS } 5 \text { years for younger patients ( } 67 \% \text { vs } 60 \% \text { ) but no difference } \\
\text { in DSS between younger and elderly patients }\end{array}$ \\
\hline $\begin{array}{l}\text { Huang et al } \\
(2009)^{9}\end{array}$ & 70 & $67 / 268$ & SR & Better OS for elderly patients \\
\hline $\begin{array}{l}\text { Kaibori et al } \\
(2009)^{46}\end{array}$ & 70 & $155 / 333$ & SR & $\begin{array}{l}\text { No difference for DFS and OS } \\
\text { More postoperative delirium in elderly patients ( } 31 \% \text { vs } 8 \% \text { ) }\end{array}$ \\
\hline $\begin{array}{l}\text { Kondo et al } \\
(2008)^{6}\end{array}$ & 70 & $109 / 210$ & SR & No difference in postoperative complications and OS \\
\hline $\begin{array}{l}\text { Ferrero et al } \\
(2005)^{47}\end{array}$ & 70 & $64 / 177$ & SR & $\begin{array}{l}\text { No difference for postoperative complications. Better } 5 \text { years OS for } \\
\text { large tumor }(>5 \mathrm{~cm}) \text { in elderly patients }(50.8 \% \text { vs } 16.1 \%)\end{array}$ \\
\hline $\begin{array}{l}\text { Nanashima et al } \\
(201 \mathrm{II})^{48}\end{array}$ & 70 & $119 / 69$ & SR & $\begin{array}{l}\text { Significantly more systemic complication after hepatectomy in elderly } \\
\text { patients }(P<0.05) \text {. No difference in survival }\end{array}$ \\
\hline $\begin{array}{l}\text { Nozawa et al } \\
(20 \mid 4)^{15}\end{array}$ & 80 & $20 / 411$ & SR & $\begin{array}{l}\text { More frequent cardiovascular complication ( } 10 \% \text { vs } 1.2 \%) \text { and delirium } \\
(30 \% \text { vs } 20 \%) \text { after hepatic resection in elderly patients. Lower rate of } \\
\text { liver and HCC-related death ( } 10 \% \text { vs } 21 \%)\end{array}$ \\
\hline $\begin{array}{l}\text { Yamada et al } \\
(2012)^{49}\end{array}$ & 80 & $11 / 267$ & SR & $\begin{array}{l}\text { No survival and postoperative complication difference between the } \\
\text { younger and elderly patients }\end{array}$ \\
\hline $\begin{array}{l}\text { Sulpice et al } \\
(2013)^{50}\end{array}$ & 75 & $152 / 760$ & SR & $\begin{array}{l}\text { More postoperative and I-year mortality in the elderly patients } \\
\text { (OR } 4.75 \text { and } 2.8 \text {, respectively). }\end{array}$ \\
\hline
\end{tabular}

Abbreviations: DFS, disease-free survival; DSS, disease-specific survival; HCC, hepatocellular carcinoma; OLT, orthotopic liver transplant; OR, odds ratio; OS, overall survival; SR, surgical resection.

postoperative complications might occur. SR seems to be safe in selected patients, with an intensive postoperative monitoring. Selection of patients for surgery might be improved by proper oncogeriatric assessment before surgery.

\section{Ablative treatments}

According to the EASL guidelines, percutaneous ablative treatment (RFA or PEI) is, after surgery, the second curative procedure for HCC BCLC 0 with tumors measuring $<2 \mathrm{~cm}$. This procedure obtains a complete response in $>90 \%$ of cases (recommendation grade as III, B).${ }^{14}$ RFA is better in terms of local control than PEI, especially for nodules measuring $>2 \mathrm{~cm}$ (recommendation grade II, A), but with the limit of five nodules and $5 \mathrm{~cm}$. The rare major complication of this procedure is the risk of bile duct damage and tumor seeding (in $0 \%-12.5 \%$ of cases, with a median of $0.9 \%$ ).

Only few papers specifically addressed the differences in outcomes after ablative treatments between elderly and younger patients, and most of them are mainly focused on RFA. ${ }^{33,51-54}$ If elderly patients have comorbidities such as vascular disease, diabetes mellitus, and chronic renal disease, it generally leads to contraindication for SR. Given its validated efficacy and low toxicity, RFA is an attractive alternative of SR for elderly patients with comorbidities.

Five studies evaluated the efficacy and safety of RFA in elderly patients with HCC. Various results were shown; Takahashi et $\mathrm{al}^{12}$ and Mirici-Cappa et $\mathrm{a}^{13}$ did not record any difference in terms of cumulative OS and relapse-free survival after RFA comparing 107 and 195 patients older than 75 with 354 and 230 younger patients, respectively, suggesting that RFA should be used for elderly patients even in case of comorbidity. Tateishi et $\mathrm{al}^{51}$ showed no difference in the 3 -year survival rate between patients aged over 68 years $(76 \%, \mathrm{n}=159)$ and under 68 years $(79 \%, \mathrm{n}=160) P=0.37$, in patients treated with RFA.

Conversely, Kao et al ${ }^{33}$ showed worse outcomes in the group of elderly patients ( 158 vs 100 patients aged more or less than 65). Especially for patients with very early stage of disease (tumor size of $2 \mathrm{~cm}$ or less, BCLC stage 0 ), the younger group presented a significantly higher OS than the elderly one due to their better liver functional reserve.

These results were supported by Sato et al,,$^{55}$ which focused on the mortality and complication rate for RFA in a large cohort of 54,145 patients with HCC, coming from the nationwide Japanese database. After a multivariate logistic regression analysis, with an age cutoff at 69 years of age, the authors found that age was significantly associated with in-hospital mortality (hazard ratio 7.05 for age 70-79 years and 8.12 for age $\geq 80$ years). Thus, advanced age would be closely associated with mortality in patients treated with RFA for HCC. Just like patients treated with surgery, patients treated with RFA should be carefully monitored during hospital stay due to the risk of induction of geriatric syndrome and mortality during hospitalizations. 


\section{Transarterial treatments}

Regarding transarterial treatments, few papers studied the specific effect of age on safety and outcomes.

\section{Hepatic artery embolization}

The only paper describing the effect of age on the outcomes after hepatic artery embolization analyzed 200 patients older than 70 versus 168 younger patients who underwent this procedure. The distribution and severity of complications were similar between the two age groups. Survival and mortality outcomes of hepatic artery embolization for the treatment of HCC were similar whether patients were aged $<70$ years or $\geq 70$ years ( $P=0.08$ and 0.82 , respectively). Although patients aged 70 years with cardiovascular comorbidities more often had a cardiopulmonary complication, other morbidity measures, including complication severity, need for intensive care unit admissions, and length of hospitalization were similar between groups. ${ }^{54}$

\section{Chemoembolization}

Regarding TACE, more studies focused on safety and outcomes in relation with age. Nishikawa et $\mathrm{al}^{56}$ compared outcomes of two groups with intermediate HCC undergoing TACE: 66 patients $\geq 75$ years and 84 patients $<75$ years. No difference in OS was observed between these two age groups, suggesting that elderly patients with intermediate HCC treated with TACE had a prognosis comparable with that of younger patients in the same context. Mirici-Cappa et $\mathrm{a}^{13}$ found similar results comparing 158 patients aged 70 years or more and 396 younger, respectively, who underwent TACE (median survival 26 vs 27 months, $P=0.73$ ). Likewise, Cohen et $\mathrm{al}^{32}$ conducted a prospective study of 102 patients divided into three age groups ( $\geq 75$ years, between 65 and 75 years, and $<65$ years) treated with TACE for unresectable HCC according to EASL criteria. No difference was seen in terms of survival and complication rates between these three patients groups, suggesting that advanced age was not associated with occurrence of complications.

Only one study showed a significant difference in OS between young ( $<70$ years) and elderly patients in a large cohort of 1,040 patients with HCC treated by TACE (197 elderly and 843 young patients), with a median OS of 8.1 versus 14.0 months, respectively $(P<0.003) .{ }^{10}$ However, regarding the TACE-related mortality, no difference was found between these two patients groups (4\% vs $3 \%$, respectively, $P=0.49)$. Thus, the authors considered that elderly patients with $\mathrm{HCC}$ treated with TACE had comparable efficacy and tolerability than younger patients.

\section{Radioembolization}

Radioembolization is an emerging treatment modality of HCC. ${ }^{57}$ Regarding radioembolization, the European Network on Radioembolization with yttrium-90 resin microspheres study group performed a retrospective study looking at results among 128 elderly (70 years or more) and 197 younger patients $(<70$ years) with unresectable HCC who received radioembolization at eight European centers. ${ }^{58}$ Radioembolization for elderly and younger patients appears to be as well-tolerated and effective in term of survival $(P=0.92)$ with a similar median survival (14.4 vs 12.8 months).

\section{Molecular targeted therapy (sorafenib)}

To date, there is a lack of data regarding the optimal management of elderly patients suffering from advanced HCC. Sorafenib is the standard care for patients with advanced HCC, regardless of age, following the results of SHARP and Asia-Pacific trials..$^{59,60}$ No specific result related to age was reported in the two major publications of this trial, and contrary to the situation in renal cell carcinoma, only few studies reported the use of sorafenib in elderly patients (Table 4). The safety of this treatment in elderly patients is poorly evaluated, but some adverse effects seem to appear more frequently in a population that presented otherwise comorbidities, which may increase treatment-related toxicity.

There is only one prospective cohort study in the literature, led by Costanzo et al, ${ }^{61}$ which compare treatment with sorafenib at the standard dose $(800 \mathrm{mg} /$ day $)$ in two groups of patients, one "young" ( $<70$ years $)$ and one "elderly" ( $\geq 70$ years). They included, respectively, 90 and 60 patients with advanced HCC or not fit for local therapies. Surprisingly, this study reported that sorafenib seems to be better tolerated and effective in the elderly group than the younger group, in terms of both time to progression and OS (12 vs 8 months and 16 vs 12 months, respectively), and considering the rate of serious side effects (9.2\% vs $15.7 \%$, respectively, for grade III or more). However, these results were not statistically significant. Three retrospective studies found similar result in terms of OS. ${ }^{62-64}$ Wong et al ${ }^{62}$ compared the efficacy and tolerability of sorafenib in 37 elderly patients aged 70 years or more and 135 younger patients, aged $<70$ years, with advanced HCC. The median progression-free survival time was similar in the two groups (3.0 vs 5.2 months, respectively, $P=0.28$ ) as the median OS (5.3 vs 5.2 months, $P=0.31$ ). No difference was seen on severe adverse effects $(68.6 \%$ and $62.7 \%$ of grade III or IV severe adverse effects in elderly and younger groups, respectively, $P=0.56$ ). Jo et $\mathrm{al}^{63}$ focused 
Table 4 Outcomes of elderly and younger patients with hepatocellular carcinoma treated with sorafenib

\begin{tabular}{|c|c|c|c|c|}
\hline $\begin{array}{l}\text { Reference } \\
\text { (year) }\end{array}$ & $\begin{array}{l}\text { Age limit } \\
\text { (years) }\end{array}$ & $\begin{array}{l}\text { Elderly/younger } \\
\text { patients (n) }\end{array}$ & Treatments & Major findings \\
\hline $\begin{array}{l}\text { Di Constanzo et al } \\
(2013)^{67}\end{array}$ & 70 & $60 / 90$ & $800 \mathrm{mg} /$ day & $\begin{array}{l}\text { No difference in TTP and OS; more grade III-IV AEs } \\
\text { in younger patients (I5.7\% vs } 9.2 \%)\end{array}$ \\
\hline $\begin{array}{l}\text { Wong et al } \\
(2011)^{62}\end{array}$ & 70 & $35 / 137$ & $800 \mathrm{mg} /$ day & $\begin{array}{l}\text { No difference in OS, median TTP, and grade III-IV } \\
A E\end{array}$ \\
\hline $\begin{array}{l}\text { Jo et al } \\
(2014)^{63}\end{array}$ & 80 & $24 / 161$ & $800 \mathrm{mg} /$ day & No difference in $\mathrm{OS}$ and $\mathrm{AE}$ \\
\hline $\begin{array}{l}\text { Morimoto et al } \\
(2011)^{65}\end{array}$ & 75 & $24 / 54$ & $800 \mathrm{mg} /$ day & $\begin{array}{l}\text { More frequent treatment interruption in elderly } \\
\text { No difference in survival }\end{array}$ \\
\hline $\begin{array}{l}\text { Edeline et al } \\
(2015)^{66}\end{array}$ & 70 & $51 / 78$ & $800 \mathrm{mg} /$ day & $\begin{array}{l}\text { More severe bleeding in elderly patients ( } 16.7 \% \\
\text { vs } 1.9 \% \text { ), especially if concomitantly used platelet } \\
\text { aggregator inhibitors }\end{array}$ \\
\hline
\end{tabular}

Abbreviations: $A E$, adverse effect; OS, overall survival; TTP, time-to-progression.

on the rare population of very elderly patients ( $\geq 80$ years). In this retrospective study, 24 very elderly patients received sorafenib for advanced HCC, compared to 161 younger ( $<80$ years). Median OS was not different in the two groups (11.7 vs 10.5 months; $P=0.45$, respectively), and the tolerance was similar. Finally, the results of a multivariate analysis from the SOFIA (SOraFenib Italian Assessment) study, including 296 patients, showed that age was not significantly associated with mortality, but it was independently related to discontinuation of therapy due to intolerance. ${ }^{64}$

Two retrospective comparative studies challenged these results, particularly regarding treatment administration. ${ }^{65,66}$ Morimoto et $\mathrm{a}^{65}$ showed in a subgroup analysis that the discontinuation rate of sorafenib therapy for advanced HCC due to serious adverse effects was more frequent among patients aged $\geq 75$ years $(42 \%)$ than among patients aged $<75$ years $(15 \%)$ treated with the standard dose of sorafenib $(800 \mathrm{mg}$ daily; $P=0.047$ ). However, this assessment did not impact the median treatment duration, the incidence of adverse effects, and the survival outcomes in the elderly group. Edeline et $\mathrm{al}^{66}$ supported these results with a retrospective study regarding efficacy and tolerability of 78 patients aged $<70$ years and 51 patients aged $\geq 70$ years treated with sorafenib at the standard dose ( $800 \mathrm{mg} /$ day) for advanced HCC. While no statistical difference was observed in terms of OS (9.6 vs 12.6 months, respectively), there was significantly less frequent definitive discontinuation of treatment due to toxicity $(24 \%$ vs $45 \%)$ in the younger group. This study also warns about the potential risk of the use of platelets inhibitor concomitant of sorafenib for elderly patients, and to closely monitor them, due to the higher frequency of bleeding observed. Major findings of these studies were summarized in Table 4.

\section{Conclusion}

Due to the progressive aging of the population, the number of elderly patients with HCC will increase in the near future. Unfortunately, international guidelines do not specifically address this aspect, which is already relevant in daily clinical practice. Importantly, elderly patients often carry comorbidities and, in clinical practice, comorbidities contribute to poor adherence to guidelines recommendations.

Available data seem to indicate that standard therapeutic option according to HCC stage, liver function, and general clinical conditions should be offered to elderly patients since the expected efficacy depends on HCC stage rather than on the actual age of the patient. In most of the studies, tolerability and efficacy were no different between older and younger patients (with a frequent cutoff of 75 years), even if some specific complications seem to be more frequent in elderly population, such as delirium, longer hospital stay, frequent discharge to a rehabilitation institution, cardiopulmonary complications, depending on the treatment option.

Thus, a nihilistic attitude of physicians toward under- or no treatment should be discouraged. It is important to note, however, that these recommendations are based on data mostly obtained in carefully selected patients.

The most effective strategy to improve management of elderly patients is probably to use appropriate tools to select these elderly patients and to adopt standardized clinical practices. The International Society of Geriatric Oncology issued in 2005 recommendations for the management of older patients with cancer. A number of validated tools were described and frequently updated. Most used of them are the G-8 score and the CGA, which are recognized as best clinical practice standard tests for the identification of frailty and are now been widely 
adopted in routine care. An elderly patient (aged 70 years or more) with HCC considered as a "fit" patient at the end of the geriatric evaluation should be treated as younger patient. If an elderly patient is considered as unfit, after the same evaluation, the treatment should be compatible with the frailty of the patient. A multidisciplinary discussion should involve geriatric specialist, nurses, oncologist, and palliative care team to offer the patient the treatment with predictable higher efficacy and adequate tolerability, always associated with supportive care. The multidisciplinary discussion also provides and coordinates an integrated plan for treatment, rehabilitation, support, and long-term care.

\section{Disclosure}

The authors report no conflicts of interest in this work.

\section{References}

1. Quaglia A, Tavilla A, Shack L, et al. The cancer survival gap between elderly and middle-aged patients in Europe is widening. Eur J Cancer. 2009;45(6):1006-1016.

2. Bosch FX, Ribes J, Díaz M, Cléries R. Primary liver cancer: Worldwide incidence and trends. Gastroenterology. 2004;127(5 Suppl 1):S5-S16.

3. Aapro MS, Köhne CH, Cohen HJ, Extermann M. Never too old? Age should not be a barrier to enrollment in cancer clinical trials. Oncologist. 2005;10(3):198-204.

4. Torre LA, Bray F, Siegel RL, Ferlay J, Lortet-Tieulent J, Jemal A. Global cancer statistics, 2012. CA Cancer J Clin. 2015;65(2): 87-108.

5. Xu XS, Chen W, Miao RC, et al. Survival analysis of hepatocellular carcinoma: a comparison between young patients and aged patients. Chin Med J (Engl). 2015;128(13):1793-1800.

6. Kondo K, Chijiiwa K, Funagayama M, Kai M, Otani K, Ohuchida J. Hepatic resection is justified for elderly patients with hepatocellular carcinoma. World J Surg. 2008;32(10):2223-2229.

7. Pignata S, Gallo C, Daniele B, et al. Characteristics at presentation and outcome of hepatocellular carcinoma (HCC) in the elderly: A study of the Cancer of the Liver Italian Program (CLIP). Crit Rev Oncol Hematol. 2006;59(3):243-249.

8. Oishi K, Itamoto T, Kohashi T, Matsugu Y, Nakahara H, Kitamoto M. Safety of hepatectomy for elderly patients with hepatocellular carcinoma. World J Gastroenterol. 2014;20(41):15028-15036.

9. Huang J, Li BK, Chen GH, et al. Long-term outcomes and prognostic factors of elderly patients with hepatocellular carcinoma undergoing hepatectomy. J Gastrointest Surg. 2009;13(9):1627-1635.

10. Yau T, Yao TJ, Chan P, et al. The outcomes of elderly patients with hepatocellular carcinoma treated with transarterial chemoembolization. Cancer. 2009;115(23):5507-5515.

11. Hiraoka A, Michitaka K, Horiike N, et al. Radiofrequency ablation therapy for hepatocellular carcinoma in elderly patients. $J$ Gastroenterol Hepatol. 2010;25(2):403-407.

12. Takahashi H, Mizuta T, Kawazoe S, et al. Efficacy and safety of radiofrequency ablation for elderly hepatocellular carcinoma patients. Hepatol Res. 2010;40(10):997-1005.

13. Mirici-Cappa F, Gramenzi A, Santi V, et al. Treatments for hepatocellular carcinoma in elderly patients are as effective as in younger patients: a 20-year multicentre experience. Gut. 2010;59(3):387-396.
14. Liver EA for the $\mathrm{S}$ of the, Cancer EO for R and T of. EASL-EORTC Clinical Practice Guidelines: Management of hepatocellular carcinoma. J Hepatol. 2012;56(4):908-943.

15. Nozawa A, Kubo S, Takemura S, et al. Hepatic resection for hepatocellular carcinoma in super-elderly patients aged 80 years and older in the first decade of the 21st century. Surg Today. 2014;45(7): $851-857$.

16. Dohmen K, Shirahama M, Shigematsu H, Irie K, Ishibashi H. Optimal treatment strategy for elderly patients with hepatocellular carcinoma. J Gastroenterol Hepatol. 2004;19(8):859-865.

17. Talarico L, Chen G, Pazdur R. Enrollment of elderly patients in clinical trials for cancer drug registration: A 7-year experience by the US Food and Drug Administration. J Clin Oncol. 2004;22(22):4626-4631.

18. Frailty in older people. Lancet. 2013;381(9868):752-762.

19. Welsh TJ, Gordon AL, Gladman JR. Comprehensive geriatric assessmenta guide for the non-specialist. Int J Clin Pract. 2014;68(3):290-293.

20. Stuck AE, Siu AL, Wieland GD, Adams J, Rubenstein LZ. Comprehensive geriatric assessment: a meta-analysis of controlled trials. Lancet. 1993;342(8878):1032-1036.

21. Ellis G, Whitehead MA, O’Neill D, Langhorne P, Robinson D. Comprehensive geriatric assessment for older adults admitted to hospital. Cochrane Database Syst Rev. 2011;(7):CD006211.

22. Decoster L, Puyvelde KV, Mohile S, et al. Screening tools for multidimensional health problems warranting a geriatric assessment in older cancer patients: an update on SIOG recommendations. Ann Oncol. 2015;26(2):288-300.

23. Bellera CA, Rainfray M, Mathoulin-Pélissier S, et al. Screening older cancer patients: first evaluation of the G-8 geriatric screening tool. Ann Oncol. 2012;23(8):2166-2172.

24. Kenis C, Decoster L, Van Puwelde KV, et al. Performance of two geriatric screening tools in older patients with cancer. J Clin Oncol. 2014;32(1):19-26.

25. Liuu E, Canouï-Poitrine F, Tournigand C, et al. Accuracy of the G-8 geriatric-oncology screening tool for identifying vulnerable elderly patients with cancer according to tumour site: The ELCAPA-02 study. J Geriatr Oncol. 2014;5(1):11-19.

26. Stokoe JM, Pearce J, Sinha R, Ring A. G8 and VES-13 scores predict chemotherapy toxicity in older patients with cancer. $J$ Geriatr Oncol. 2012;3(Suppl 1):S81.

27. Soubeyran P, Bellera C, Goyard J, et al. Validation of the G8 screening tool in geriatric oncology: The ONCODAGE project. J Clin Oncol. 2011;29(15_Suppl):9001.

28. Saliba D, Elliott M, Rubenstein LZ, et al. The vulnerable elders survey: a tool for identifying vulnerable older people in the community. $\mathrm{J} \mathrm{Am}$ Geriatr Soc. 2001;49(12):1691-1699.

29. Huisman MG, Audisio RA, Ugolini G, et al. Screening for predictors of adverse outcome in onco-geriatric surgical patients: A multicenter prospective cohort study. Eur J Surg Oncol. 2015;41(7): 844-851.

30. Pottel L, Boterberg T, Pottel H, et al. Determination of an adequate screening tool for identification of vulnerable elderly head and neck cancer patients treated with radio(chemo)therapy. J Geriatr Oncol. 2012;3(1):24-32.

31. Honda T, Miyaaki H, Ichikawa T, et al. Clinical characteristics of hepatocellular carcinoma in elderly patients. Oncol Lett. 2011;2(5):851-854.

32. Cohen MJ, Bloom AI, Barak O, et al. Trans-arterial chemo-embolization is safe and effective for very elderly patients with hepatocellular carcinoma. World J Gastroenterol. 2013;19(16):2521-2528.

33. Kao WY, Chiou YY, Hung HH, et al. Younger hepatocellular carcinoma patients have better prognosis after percutaneous radiofrequency ablation therapy. J Clin Gastroenterol. 2012;46(1):62-70.

34. Su CW, Lei HJ, Chau GY, et al. The effect of age on the long-term prognosis of patients with hepatocellular carcinoma after resection surgery: A propensity score matching analysis. Arch Surg. 2012;147(2):137-144. 
35. Nishikawa H, Arimoto A, Wakasa T, Kita R, Kimura T, Osaki Y. Surgical resection for hepatocellular carcinoma: clinical outcomes and safety in elderly patients. Eur J Gastroenterol Hepatol. 2013;25(8): 912-919.

36. Reddy SK, Barbas AS, Turley RS, et al. Major liver resection in elderly patients: a multi-institutional analysis. $J$ Am Coll Surg. 2011;212(5):787-795.

37. Nishikawa H, Kimura T, Kita R, Osaki Y. Treatment for hepatocellular carcinoma in elderly patients: a literature review. $J$ Cancer. 2013;4(8):635-643.

38. Alexia C, Fallot G, Lasfer M, Schweizer-Groyer G, Groyer A. An evaluation of the role of insulin-like growth factors (IGF) and of type-I IGF receptor signalling in hepatocarcinogenesis and in the resistance of hepatocarcinoma cells against drug-induced apoptosis. Biochem Pharmacol. 2004;68(6):1003-1015.

39. van der Poorten D, Milner KL, Hui J, et al. Visceral fat: A key mediator of steatohepatitis in metabolic liver disease. Hepatology. 2008;48(2):449-457.

40. Reduction of telomeric repeats as a possible predictor for development of hepatocellular carcinoma: Convenient evaluation by slot-blot analysis. Isokawa; 2003. Hepatology; Wiley Online Library. Available from: http://onlinelibrary.wiley.com.passerelle.univ-rennes1.fr/doi/10.1002/ hep.510300211/abstract?systemMessage=Wiley+Online+Library+wil 1+have+intermittent+access +on +8 th + August $+2015+$ from $+10 \% 3 \mathrm{~A} 00$ $16 \% 3 \mathrm{~A} 00+\mathrm{BST}+\% 2 \mathrm{~F}+05 \% 3 \mathrm{~A} 00-11 \% 3 \mathrm{~A} 00+\mathrm{EDT}+\% 2 \mathrm{~F}+17 \% 3 \mathrm{~A} 00-$ $23 \% 3 \mathrm{~A} 00+\mathrm{SGT}+$ for+essential+maintenance. ++ Apologies + for + the $+\mathrm{i}$ nconvenience. Accessed August 7, 2015.

41. Keswani RN, Ahmed A, Keeffe EB. Older age and liver transplantation: A review. Liver Transpl. 2004;10(8):957-967.

42. Kim J, Ko ME, Nelson RA, et al. Increasing age and survival after orthotopic liver transplantation for patients with hepatocellular cancer. J Am Coll Surg. 2014;218(3):431-438.

43. Ishizawa T, Mise Y, Aoki T, et al. Surgical technique: new advances for expanding indications and increasing safety in liver resection for HCC. J Hepatobiliary Pancreat Sci. 2010;17(4):389-393.

44. Cescon M, Grazi GL, Del Gaudio M, et al. Outcome of right hepatectomies in patients older than 70 years. Arch Surg. 2003;138(5):547-552.

45. Shirabe K, Kajiyama K, Harimoto N, et al. Early outcome following hepatic resection in patients older than 80 years of age. World J Surg. 2009;33(9):1927-1932.

46. Kaibori M, Matsui K, Ishizaki M, et al. Hepatic resection for hepatocellular carcinoma in the elderly. J Surg Oncol. 2009;99(3):154-160.

47. Ferrero A, Viganò L, Polastri R, et al. Hepatectomy as treatment of choice for hepatocellular carcinoma in elderly cirrhotic patients. World J Surg. 2005;29(9):1101-1105.

48. Nanashima A, Abo T, Nonaka T, et al. Prognosis of patients with hepatocellular carcinoma after hepatic resection: Are elderly patients suitable for surgery? J Surg Oncol. 2011;104(3):284-291.

49. Yamada S, Shimada M, Miyake H, et al. Outcome of hepatectomy in super-elderly patients with hepatocellular carcinoma. Hepatol Res. 2012;42(5):454-458.

50. Sulpice L, Rayar M, Campillo B, et al. Advanced age remains an Achilles heel for liver resections. World J Surg. 2013;38(4):918-926.
51. Tateishi R, Shiina S, Teratani T, et al. Percutaneous radiofrequency ablation for hepatocellular carcinoma. Cancer. 2005;103(6):1201-1209.

52. Shiina S, Tateishi R, Arano T, et al. Radiofrequency ablation for hepatocellular carcinoma: 10-year outcome and prognostic factors. $\mathrm{Am} J$ Gastroenterol. 2012;107(4):569-577.

53. De Giorgio M, Vezzoli S, Cohen E, et al. Prediction of progression-free survival in patients presenting with hepatocellular carcinoma within the Milan criteria. Liver Transpl. 2010;16(4):503-512.

54. Thornton RH, Covey A, Petre EN, et al. A comparison of outcomes from treating hepatocellular carcinoma by hepatic artery embolization in patients younger or older than 70 years. Cancer. 2009;115(21):5000-5006

55. Sato M, Tateishi R, Yasunaga $\mathrm{H}$, et al. Mortality and morbidity of hepatectomy, radiofrequency ablation, and embolization for hepatocellular carcinoma: a national survey of 54,145 patients. J Gastroenterol. 2012;47(10):1125-1133.

56. Nishikawa H, Kita R, Kimura T, et al. Transcatheter arterial chemoembolization for intermediate-stage hepatocellular carcinoma: clinical outcome and safety in elderly patients. J Cancer. 2014;5(7):590-597.

57. Mahvash A, Murthy R, Odisio BC et al. Yttrium-90 resin microspheres as an adjunct to sorafenib in patients with unresectable hepatocellular carcinoma. J Hepatocell Carcinoma. 2016;3:1-7.

58. Hilgard P, Hamami M, Fouly AE, et al. Radioembolization with yttrium-90 glass microspheres in hepatocellular carcinoma: European experience on safety and long-term survival. Hepatology. 2010;52(5):1741-1749.

59. Bruix J, Raoul JL, Sherman M, et al. Efficacy and safety of sorafenib in patients with advanced hepatocellular carcinoma: Subanalyses of a phase III trial. J Hepatol. 2012;57(4):821-829.

60. Llovet JM, Ricci S, Mazzaferro V, et al. Sorafenib in advanced hepatocellular carcinoma. $N$ Engl J Med. 2008;359(4):378-390.

61. Di Costanzo GG, Tortora R, De Luca MD, et al. Impact of age on toxicity and efficacy of sorafenib-targeted therapy in cirrhotic patients with hepatocellular carcinoma. Med Oncol. 2013;30(1):446.

62. Wong H, Tang YF, Yao TJ, et al. The outcomes and safety of single-agent sorafenib in the treatment of elderly patients with advanced hepatocellular carcinoma (HCC). Oncologist. 2011;16(12):1721-1728.

63. Jo M, Yasui K, Kirishima T, et al. Efficacy and safety of sorafenib in very elderly patients aged 80 years and older with advanced hepatocellular carcinoma. Hepatol Res. 2014;44(13):1329-1338.

64. Iavarone M, Cabibbo G, Piscaglia F, et al. Field-practice study of sorafenib therapy for hepatocellular carcinoma: A prospective multicenter study in Italy. Hepatology. 2011;54(6):2055-2063.

65. Morimoto M, Numata K, Kondo M, et al. Higher discontinuation and lower survival rates are likely in elderly Japanese patients with advanced hepatocellular carcinoma receiving sorafenib. Hepatol Res. 2011;41(4):296-302.

66. Edeline J, Crouzet L, Le Sourd S, et al. Sorafenib use in elderly patients with hepatocellular carcinoma: caution about use of platelet aggregation inhibitors. Cancer Chemother Pharmacol. 2015;75(1):215-219.

67. Di Costanzo GG, Tortora R, De Luca M, et al. Impact of age on toxicity and efficacy of sorafenib-targeted therapy in cirrhotic patients with hepatocellular carcinoma. Med Oncol. 2013;30(1)446.

Journal of Hepatocellular Carcinoma

\section{Publish your work in this journal}

The Journal of Hepatocellular Carcinoma is an international, peerreviewed, open access journal that offers a platform for the dissemination and study of clinical, translational and basic research findings in this rapidly developing field. Development in areas including, but not limited to, epidemiology, vaccination, hepatitis therapy, pathology and

molecular tumor classification and prognostication are all considered for publication. The manuscript management system is completely online and includes a very quick and fair peer-review system, which is all easy to use. Visit http://www.dovepress.com/testimonialsphp to read real quotes from published authors. 